\title{
Associations of physical activity and sedentary behaviors with child mental well- being during the COVID-19 pandemic
}

Amanda S. Gilbert ${ }^{*}$ D, Laurel Schmidt, Alan Beck, Maura M. Kepper, Stephanie Mazzucca and Amy Eyler

\begin{abstract}
Background: The COVID-19 pandemic resulted in public health and policy measures to reduce in-person contact and the transmission of the virus. These measures impacted daily life and mental well-being (MWB). The aims of this study were to explore the MWB impacts of COVID-19 on children and assess the associations among perceived changes in physical activity (PA) and sedentary behaviors (SB), with perceived MWB changes, using a mixedmethods approach.

Methods: A convergent parallel mixed-methods design consisting of an online survey with a convenience sample and interviews was conducted from May through July 2020 with parents/caregivers of kindergarten through 5th graders in the St. Louis region. Survey domains assessed included child MWB, PA, and SB. Interviews were recorded, transcribed, and qualitatively analyzed using a code book developed to elicit themes. Survey data was analyzed with chi-squared tests and logistic regressions. The dependent variable was perceived change in child MWB due to the impact of COVID-19. Independent variables included perceived changes in PA, SB, and child concerns about COVID-19.
\end{abstract}

Results: Sample size consisted of 144 surveys and 16 interviews. Most parents reported a perceived decrease in child MWB (74\%), a decrease in child PA (61\%), and an increase in child SB (91\%). Discontentment with stay-athome orders and concern about COVID-19 were associated with a perceived decrease in MWB. Children whose PA decreased were $53 \%$ less likely to have the same or better MWB (OR 0.47) and children whose outside PA decreased were $72 \%$ less likely to have the same or better MWB (OR 0.28). Common qualitative themes included difficulty in adjusting to COVID-19 restrictions due to school closures and lack of socializing, child concerns about family getting sick, and PA benefits for improving MWB.

Conclusions: Based on parent perceptions, MWB decreased with COVID-19. Maintained or increased child PA improved the chances MWB would remain the same or improve. Parent interviews provide context to these findings by showing how COVID-19 impacted MWB and the associations between PA and MWB. Understanding protective factors for child MWB during COVID-19 is important to offset negative long-term health outcomes from this ongoing pandemic.

Keywords: Mixed-methods, Child, Mental well-being, Physical activity, Sedentary behavior, COVID-19

\footnotetext{
* Correspondence: a.s.gilbert@wustl.edu

Prevention Research Center in St. Louis, Brown School at Washington

University in St. Louis, St. Louis, MO, USA
}

(c) The Author(s). 2021 Open Access This article is licensed under a Creative Commons Attribution 4.0 International License, which permits use, sharing, adaptation, distribution and reproduction in any medium or format, as long as you give appropriate credit to the original author(s) and the source, provide a link to the Creative Commons licence, and indicate if changes were made. The images or other third party material in this article are included in the article's Creative Commons licence, unless indicated otherwise in a credit line to the material. If material is not included in the article's Creative Commons licence and your intended use is not permitted by statutory regulation or exceeds the permitted use, you will need to obtain permission directly from the copyright holder. To view a copy of this licence, visit http://creativecommons.org/licenses/by/4.0/. The Creative Commons Public Domain Dedication waiver (http://creativecommons.org/publicdomain/zero/1.0/) applies to the data made available in this article, unless otherwise stated in a credit line to the data. 


\section{Background}

Beginning in December 2019, the respiratory disease SARS-CoV-2 virus (COVID-19) began spreading around the world. Since then, the World Health Organization has reported over 200 million cases and over 4 million deaths worldwide, with the Centers for Disease Control and Prevention reporting over 36.7 million cases and around 620,000 deaths in the United States (US) as of August 15, 2021 [1, 2]. To prevent COVID-19 transmission in the US, public health measures such as stay-at-home orders, closures of non-essential businesses, in-person school, and many other public places have been implemented to restrict in-person contact. These restrictions are ongoing and have had a significant impact on daily life and well-being [3-5]. Preliminary research in the first few months of the COVID-19 pandemic identified child mental well-being (MWB) as being particularly vulnerable to the pandemic and associated public health restrictions [6-11]. Children face social isolation, educational delays from in-person school closures, and stress from financial strains many families experience because of parents and caregivers losing work due to COVID-19 restrictions [7, 10, 12, 13]. Additionally, children of elementary school age may have a hard time understanding the health risks of COVID-19 and changes to daily life from lockdown measures, further increasing fear and anxiety [6]. COVID-19 restrictions are also associated with increased sedentary behavior (SB) and decreased physical activity (PA), which further increase the risk for poor mental health and well-being in children [14-20].

The full impacts of COVID-19 on MWB, PA, and SB are still unknown; however, evidence suggests poor MWB, limited PA, and increased SB in childhood may have potentially long-term and serious health consequences [21-26]. Children who do not meet recommended PA guidelines (i.e., 60 min of moderate-vigorous PA per day) are at an increased risk of developing mental health disorders, such as depression and anxiety, as well as chronic diseases, including obesity, diabetes, and cardiovascular disease later in life [22, 27]. Children not only need regular PA to improve health and well-being, but can be vulnerable to decreased cognitive functioning, obesity, and cardiometabolic risk factors if they spend significant amounts of time being sedentary (e.g. sitting, watching TV, on the computer) [27-29].

The COVID-19 pandemic and associated restrictions are ongoing with no clear timeframe for when restrictions will be lifted, making the potential impacts on child MWB, PA, and SB with the subsequent long-term effects on health and well-being particularly concerning. Given this, the aims of this study were 1) to explore how COVID-19 restrictions are impacting child MWB, PA, and SB using qualitative methods, and 2) to assess how perceived changes in $\mathrm{PA}$ and $\mathrm{SB}$ due to COVID-19 restrictions are associated with perceived changes in MWB using quantitative methods.

\section{Methods \\ Study design}

This was a convergent parallel mixed-methods study to assess the impact of COVID-19 on child MWB and associations with PA and SB. Convergent parallel designs consist of conducting qualitative and quantitative methods independently and concurrently, with results from each of these methods being integrated during the interpretation of findings [30]. The purpose of using this design was to triangulate results from each method, and to further understand the context of quantitative results through qualitative findings. Online surveys were conducted with parents and caregivers of children in kindergarten through 5th grade to assess the association among perceived changes in PA and SB, and perceived MWB changes. Surveys were conducted concurrently with the same population to explore the MWB impacts of COVID-19 on children. Following analysis, results from the online survey and interviews were integrated to inform study interpretations.

\section{Recruitment and participants}

Participants for the online survey were recruited using convenience sampling. The survey link was posted on Twitter and Facebook and distributed on Facebook to St. Louis-based neighborhood groups for parents with elementary school children. Sampling methods focused on parents and caregivers in the St. Louis region with children enrolled in kindergarten through 5th grade. The survey was available from late May to early July 2020 for approximately 8 weeks. Participants had the option of providing email addresses. Interviews were conducted independently during this time period within the same population, using a combination of convenience and snowball sampling. Participants were contacted via phone and email. The Institution Review Board of Washington University in St. Louis approved this study with an exempt status.

\section{Procedures}

Participants completed the online survey via Qualtrics. All surveys were anonymous and consisted of a consent page and information regarding the purpose of the study. The online survey was developed for this study (see Supplement 1). The survey consisted of 63 questions and took between 15 and 20 minutes to complete. Topics in the survey included parent, child, and household demographics, child MWB, child PA and SB, as well as parental influence and rules regarding these behaviors. Qualitative interviews $(n=16)$ were administered via telephone or Zoom and lasted between 20 and 
$30 \mathrm{~min}$. Parents were provided the consent form and reason for this study prior to the interview. Participants completed the interviews from their homes in privacy. No repeat interviews were conducted. Interviews were conducted until saturation was reached. Interviews were audio recorded for accuracy, de-identified, and then professionally transcribed verbatim. If participants had more than one child, participants were asked to choose one child to answer questions for. Questions asked during the interviews were informed by early COVID-19 research and developed with expertise of the research team. Questions covered similar topics to the online survey, along with more open-ended explorations around how the COVID-19 pandemic impacted their families and children.

\section{Measures}

\section{Perceived changes in child MWB}

Quantitative An adapted version of the parent-report on child Mood and Feelings Questionnaire was used to measure child MWB [31]. Items in the measure were chosen based on face value relevance for measuring COVID-19 impact and stems were modified to focus on the time period prior to and during COVID-19 restrictions. Parents were asked to answer whether statements were true, sometimes true, or not true about their child. The questionnaire consisted of 9 statements regarding whether the child was miserable or unhappy, not enjoying anything at all, tired, very restless, finding it hard to think properly and concentrate, lonely, irritable or angry, worried a lot, and having trouble sleeping. Parents filled out this questionnaire based on perceptions of how their child felt prior to and during COVID-19 restrictions. Scores were given to each answer (true $=2$, sometimes true $=1$, not true $=0$ ), and added up to create MWB scores for before and during COVID-19 restrictions. Higher scores indicated worse MWB. To get changes in MWB, the total MWB score for each child during COVID-19 restrictions was subtracted from the total MWB score prior to COVID-19 restrictions and then dichotomized into same or better MWB and worse MWB.

Qualitative Interviews assessed child MWB by asking parents about their child's general mood and how their child's mood had been impacted by COVID-19 restrictions. Questions were meant to elicit qualitative responses on how parents perceived their child's MWB and to explore context around why or how MWB might be impacted by COVID-19 restrictions. Follow up questions were often asked about the impact of school closures, and what parents found to be helpful for improving MWB during COVID-19 restrictions. If parents noted worsening MWB, follow up questions were asked to elicit more information about why these changes to MWB occurred.

\section{COVID-19 concerns}

Quantitative The online survey assessed COVID-19 concerns by asking parents to report on whether statements such as, my child has not been content with stayat-home orders, was afraid of self/family/friends getting sick, was concerned about COVID-19, and talked/asked questions about COVID-19, were true, sometimes true, or not true.

Qualitative In interviews with parents, COVID-19 concerns were explored by asking parents about their child's level of concern regarding COVID-19, their understanding, and what questions and concerns their child voiced about COVID-19.

\section{Perceived changes in PA and $S B$}

Quantitative To measure parent perceptions of changes in child PA and SB, questions from an existing scale, the HomeSTEAD's physical activity and screen media practices and beliefs survey were used [32]. Parents were asked in the online survey whether their child's PA increased, stayed the same, or decreased due to COVID19 restrictions. Specific PA behaviors and SB were measured by asking parents to report on the daily number of minutes for activities during COVID-19 restrictions and whether that amount of time was less, more, or about the same as it was prior to the COVID-19 pandemic. PA behaviors included playing inside, playing outside, participating in sports and organized activities, and playing outdoors as a family. SB included using screens (e.g. TV, tablet, computer, smartphone, video games) for entertainment, using screens for educational purposes, and time spent sitting.

Qualitative During interviews parents were asked to describe their child's current level of PA, and if their child's PA level had changed due to COVID-19 restrictions. If parents perceived changes to child PA, follow up questions were asked about how COVID-19 restrictions impacted PA levels. Parents were also asked to describe the types of activities their child engaged in during COVID19 restrictions and how these activities differed from before COVID-19 restrictions. Parents were also asked about $\mathrm{SB}$ and how much their child spent time using screens for school and entertainment during COVID-19 restrictions. Follow up questions assessed whether this was different prior to COVID-19 and if so, what the changes had been. Similar questions were asked about 
non-screen time sedentary activities (e.g. reading, coloring, building blocks).

\section{Analysis}

Quantitative data analysis was conducted using SPSS (version 26). The dependent variable was perceived change in MWB. Independent variables included in the analysis were PA behaviors (perceived change in PA, perceived change in organized sports, perceived change in outside play, perceived change in inside play, and perceived change in family PA), SB (perceived change in time sitting, perceived change in screen time for entertainment, and perceived change in screen time for education), and COVID-19 concerns (discontent with stayat-home orders, concern about COVID-19, and fear of family/self/friends getting sick). PA and SB were dichotomized into binary variables of 'same or increased' and 'decreased'. COVID-19 concerns were also dichotomized into 'sometimes true or true' and 'not true'. Descriptive statistics, frequency tables, and chi-square analyses were conducted. The McNemar test was run to determine if there were statistically significant differences between each MWB item of the Mood and Feelings questionnaire reported for prior to COVID-19 restrictions compared to during COVID-19 restrictions. For statistically significant correlations, logistic regressions were conducted to determine the association between PA, SB, and COVID19 concerns with perceived change in MWB. Adjusted models were also run controlling for age and gender.

Qualitative analysis of the transcripts began with three rounds of preliminary analysis to develop the qualitative code book. In the first round, we used an open coding method, were a priori codes were developed based on categories of interview questions from the interview guide. In the second round, two research team members reviewed all transcripts and collaborated to add more detailed codes to existing categories. Additional categories for codes were added as needed. In the third round, two research team members used this initial codebook to double-code three transcripts. The two team members then reviewed the coding to identify any gaps in the codebook or differences in coding. Once consensus on coding was established, the codebook was finalized, and a third research team member was trained to use the final codebook. Using the final codebook, each transcript was double-coded by the three members of the research team and reviewed to eliminate discrepancies between reviewers. Coded text was separated out by code to be reviewed for common themes by research team members. Common themes were discussed and agreed upon through consensus. These themes were then compared to the quantitative findings and integrated by identifying convergence and places where qualitative rich text could be used to provide context for quantitative results.

\section{Results}

The total number of parents surveyed was 245 . The final sample consists of the 144 respondents who completed the child Mood and Feelings Questionnaire. The final analytic sample was not significantly different than the total sample of parents surveyed for demographic variables of child age, race, gender, and ethnicity. Table 1 lists the descriptive statistics for the demographic variables of the sample. The ages of children in the quantitative sample ranged from five to twelve years old, with an average age of $8 \quad(\mathrm{SD}=1.75)$. A majority of children (96\%) were white, $44 \%$ were female, and most $(74 \%)$ lived in a household with two to three children. Most of the parents/caregivers surveyed were female (88\%), ranging in age from 30 to 51 years old with an average parental age of $40(\mathrm{SD}=4.17)$. The majority were white

Table 1 Baseline characteristics of child mental well-being survey sample

\begin{tabular}{|c|c|}
\hline \multicolumn{2}{|l|}{ Quantitative survey $(n=144)$} \\
\hline \multicolumn{2}{|l|}{ Child characteristics } \\
\hline Age, years M (SD) & $8.01(1.75)$ \\
\hline Female, n (\%) & $64(44.44)$ \\
\hline White, n (\%) & $138(95.83)$ \\
\hline \multicolumn{2}{|l|}{ Children in household, n (\%) } \\
\hline One & $21(14.58)$ \\
\hline Two-Three & $106(73.61)$ \\
\hline Four or more & $17(11.81)$ \\
\hline \multicolumn{2}{|l|}{ Parent characteristics } \\
\hline Age, years M (SD) & $39.76(4.17)$ \\
\hline Female, n (\%) & $126(87.50)$ \\
\hline White, $\mathrm{n}(\%)$ & $138(95.80)$ \\
\hline Hispanic, Latino, or Spanish origin n (\%) & $9(6.30)$ \\
\hline Married, living with partner, n (\%) & $134(93.10)$ \\
\hline Employed, n (\%) & $120(83.33)$ \\
\hline \multicolumn{2}{|l|}{ Employment Location, n (\%) } \\
\hline Outside of home & $22(16.20)$ \\
\hline At home & $95(69.90)$ \\
\hline Both at \& outside of home & $19(14.00)$ \\
\hline \multicolumn{2}{|l|}{ Qualitative interviews $(n=16)$} \\
\hline \multicolumn{2}{|l|}{ Child characteristics } \\
\hline Age, years M (SD) & $7(0.71)$ \\
\hline Female, n (\%) & $13(56.50)^{a}$ \\
\hline Households with more than one child, n (\%) & $14(87.50)$ \\
\hline \multicolumn{2}{|l|}{ Parent characteristics } \\
\hline Female, n (\%) & $15(93.75)$ \\
\hline Married, n (\%) & $13(81.25)$ \\
\hline
\end{tabular}

Parents reported on a total of 23 elementary school aged children 
(96\%), married or living with a partner $(93 \%)$, and employed (83\%).

Sixteen qualitative interviews were conducted with parents who had children ranging in age from four to 11 years old, with an average age of $7(\mathrm{SD}=0.71)$. Parents reported on a total of 23 elementary school aged children, 13 of which were female. Overall, $87 \%$ of households had more than one child. Parents interviewed were mostly female (94\%) and married (81\%). Parents reported a wide range of jobs from social worker and teacher, to IT consultant, attorney, and business owner. Most reported working from home and a few noted being laid off or furloughed due to the COVID-19 pandemic.

\section{Quantitative results}

Overall, $74 \%$ of parents reported their children had worse MWB during COVID-19 restrictions (see Table 2). The majority of parents (75\%) reported their child was discontent with stay-at-home orders. Most parents (76\%) reported their child was concerned about COVID19 and $63 \%$ were afraid for themselves or a family member getting sick. Each MWB item in the adapted Mood and Feelings questionnaire was reported to be worse during COVID-19 restrictions. Among aspects of child MWB, perceived loneliness increased the most, from less than $1 \%$ prior to COVID-19 restrictions to 33\% during COVID-19 restrictions. Other aspects of child MWB perceived to worsen the most were anger, difficulty concentrating, restlessness, difficulty sleeping, and unhappiness.

Results from chi-squared and logistic regression analyses are presented in Table 3. Discontentment $\left(x^{2}(2)=\right.$ 8.06, $p=0.005)$ and concern $\left(x^{2}(2)=7.20, p=0.007\right)$ about COVID-19 were significantly associated with perceived changes in MWB. Among PA behaviors surveyed, perceived changes in PA $\left(x^{2}(2)=4.10, p=0.043\right)$, perceived changes in organized sports $\left(x^{2}(2)=5.61, p=\right.$

Table 2 Frequencies of parent reported child MWB, PA, and SB before and during COVID- 19 restrictions $(n=144)$

\begin{tabular}{|c|c|c|c|}
\hline & Pre- COVID-19 & During COVID-19 & $P$-value ${ }^{a}$ \\
\hline \multicolumn{4}{|l|}{ Mental well-being, $\mathrm{n}(\%)^{\mathbf{b}}$} \\
\hline Lonely & $1(0.69)$ & $48(33.33)$ & $<0.001$ \\
\hline Unhappy & $1(0.69)$ & $16(11.11)$ & $<0.001$ \\
\hline Lack enjoyment & $1(0.69)$ & $9(6.25)$ & $<0.01$ \\
\hline Tired & $0(0.00)$ & $10(6.94)$ & $<0.001$ \\
\hline Restless & $7(4.86)$ & $27(18.75)$ & $<0.001$ \\
\hline Difficulty concentrating & $9(6.25)$ & $31(21.52)$ & $<0.001$ \\
\hline Difficulty sleeping & $2(1.39)$ & $20(13.88)$ & $<0.001$ \\
\hline Worried & $6(4.17)$ & $25(17.36)$ & $<0.001$ \\
\hline Angry & $4(2.78)$ & $30(20.83)$ & $<0.001$ \\
\hline \multicolumn{4}{|c|}{ COVID-19 specific mental well-being, $n(\%)^{b}$} \\
\hline Discontent $^{c}$ & & $108(75.00)$ & . \\
\hline Concerned $^{d}$ & & $110(76.39)$ & \\
\hline Afraid $^{e}$ & . & $90(62.50)$ & . \\
\hline \multicolumn{4}{|c|}{ Change in mental well-being, $n(\%)^{f}$} \\
\hline Same or better & . & $38(26.39)$ & . \\
\hline Worse & . & $106(73.61)$ & \\
\hline \multicolumn{4}{|c|}{ Change in physical activity, $n(\%)^{f}$} \\
\hline Same or increase & . & $56(38.89)$ & . \\
\hline Decrease & & $88(61.11)$ & . \\
\hline \multicolumn{4}{|c|}{ Change in time spent sitting, $n(\%)^{f}$} \\
\hline Same or increase & & $115(91.26)$ & . \\
\hline Decrease & . & $11(8.73)$ & . \\
\hline
\end{tabular}

MWB Mental well-being, PA Physical activity, SB Sedentary behavior

${ }^{\mathrm{a}}$ McNemar test

${ }^{b}$ Parents reporting if mental well-being component was sometimes true or true about their child

'Discontent with stay-at-home orders

${ }^{\mathrm{d}}$ Concerned about COVID-19

${ }^{\mathrm{e}}$ Afraid of self or family getting sick

fPerceptions of change based on questions asking parents to report on child behavior and mental well-being prior to and during COVID-19 restrictions 
Table 3 Analyses of COVID-19 concern, PA, and SB with perceived change in MWB during COVID-19 $(n=144)$

\begin{tabular}{|c|c|c|c|c|c|c|c|}
\hline & \multirow{2}{*}{$\begin{array}{l}\text { Correlation } \\
\text { Coefficient (R) }\end{array}$} & \multicolumn{3}{|c|}{ Unadjusted models } & \multicolumn{3}{|c|}{ Models adjusted for age } \\
\hline & & B (SE) & OR & $95 \% \mathrm{Cl}$ & B (SE) & OR & $95 \% \mathrm{Cl}$ \\
\hline \multicolumn{8}{|l|}{ COVID-19 concern $^{a}$} \\
\hline Discontent & $8.06^{* *}$ & $-1.14(0.41)$ & $0.32^{* *}$ & $0.14,0.72$ & $-1.14(0.41)$ & $0.32^{* *}$ & $0.14,0.72$ \\
\hline Concerned & $7.20^{* *}$ & $-1.09(0.42)$ & $0.34^{* *}$ & $0.15,0.76$ & $-1.11(0.42)$ & $0.33^{* *}$ & $0.15,0.75$ \\
\hline Afraid & 3.44 & . & . & . & & . & . \\
\hline \multicolumn{8}{|l|}{ PA behaviors ${ }^{b}$} \\
\hline Decrease in PA & $4.10^{*}$ & $-0.77(0.38)$ & $0.46^{*}$ & $0.22,0.98$ & $-0.77(0.38)$ & $0.47^{*}$ & $0.22,0.99$ \\
\hline Decrease in organized sports & $5.61^{*}$ & $-1.05(0.45)$ & $0.35^{*}$ & $0.14,0.85$ & $-1.07(0.46)$ & $0.34^{*}$ & $0.14,0.84$ \\
\hline Decrease in outside play & $6.35^{*}$ & $-1.27(0.53)$ & $0.28^{*}$ & $0.10,0.79$ & $-1.26(0.53)$ & $0.28^{*}$ & $0.10,0.80$ \\
\hline Decrease in inside play & 1.22 & . & & & & & \\
\hline Decrease in family PA & 0.81 & & . & . & & . & \\
\hline \multicolumn{8}{|l|}{$\mathrm{SB}^{\mathrm{c}}$} \\
\hline Same or increase in time sitting & $4.65^{*}$ & $-1.32(0.64)$ & $0.27^{*}$ & $0.08,0.95$ & $-1.22(0.65)$ & 0.30 & $0.08,1.06$ \\
\hline Same or increase in screen time for entertainment & 0.00 & . & & & & & \\
\hline Same or increase in screen time for education & 1.31 & & . & . & & . & \\
\hline
\end{tabular}

Statistical Significance at the $P<0.05\left(^{*}\right), p<0.01\left(^{* *}\right)$ level

$P A$ Physical activity, $S B$ Sedentary behaviors, $M W B$ Mental well-being

MWB, PA, and SB changes are perceived changes based on questions asking parents to report on child MWB, PA, and SB prior to and during COVID-19 restrictions ${ }^{a}$ Reference group for COVID-19 concern (not true)

${ }^{\mathrm{b}}$ Reference group for PA behaviors (same or increase)

'Reference group for SB (decrease)

$0.018)$, and perceived changes in outside play $\left(x^{2}(2)=\right.$ $6.35, p=0.012$ ), were significantly associated with perceived changes in MWB. Among SB, only a perceived change in time spent sitting $\left(x^{2}(2)=4.65, p=0.031\right)$ was statistically significant.

Logistic regressions were conducted for all statistically significant correlations. Models were adjusted for age and gender to control for potential confounding of these demographic factors. Overall, outcomes did not change significantly after adjusting for age and gender. However, there was evidence of confounding by age for change in sitting. Therefore, results are presented for both unadjusted and age-adjusted models (Table 3). We found children whose parents reported them to be discontent with stay-at-home orders were $68 \%$ less likely to have the same or better MWB during COVID-19 restrictions compared to children who were content with stay-athome orders $(\mathrm{OR}=0.32$, 95CI 0.14-0.72). Similarly, if a child was concerned about COVID-19, they were $67 \%$ less likely to have the same or better MWB during COVID-19 restrictions compared to a child who was not concerned about COVID-19 (OR $=0.33$, 95CI 0.150.75). In terms of PA behaviors, if a child's perceived PA decreased following COVID-19 restrictions, they were $53 \%$ less likely to have the same or better MWB than a child whose perceived PA stayed the same or increased $(\mathrm{OR}=0.47$, 95CI 0.22-0.99). Similarly, if a parent perceived a child's participation in organized sports decreased, they were $66 \%$ less likely to have the same or better MWB during COVID-19 restrictions than a child whose perceived participation in organized sports stayed the same or increased (OR $=0.34$, 95CI 0.14-0.84). A child whose parents perceived a decrease in playing outside during COVID-19 restrictions were $72 \%$ less likely to have the same of better MWB during COVID-19 restrictions than a child whose perceived time playing outside stayed the same or increased $(\mathrm{OR}=0.28$, 95CI 0.10 0.80). Regarding SB, time spent sitting was no longer significant after adjusting for age $(\mathrm{OR}=0.30$, 95CI 0.08 1.06).

\section{Qualitative results}

Themes from qualitative interviews provided context to how COVID-19 restrictions impacted children's MWB and elucidated protective factors which minimized the impact of COVID-19 (Table 4). A prominent theme revolved around the adjustment to stay-at-home orders and COVID-19 restrictions. Many parents reported their children feeling frustrated by COVID-19 restrictions and having difficulty adjusting to online school and a lack of peer interactions. Parents reported it was difficult for children to adapt to this new routine and often complained of missing friends and school. Some parents reported children being emotionally up and down or regressing due to a lack of social interaction they would have had at school. When discussing the upcoming school year, many parents reported their children were disappointed about the prospect of not returning to in- 
Table 4 Child mental well-being themes during COVID-19 restrictions

\begin{tabular}{ll}
\hline Theme & Sub-Themes \\
\hline Adjusting to COVID-19 & Limitations \\
restrictions & -no in-person school \\
& -change in routine \\
& Boredom/Monotony \\
& -stuck at home \\
& -online school \\
& Lack of Socializing \\
& -no in-person interaction \\
& -no organized sports
\end{tabular}

\section{Definition}

The impact of COVID-19 and SAH orders

on daily life. This includes in-person school closures, park closures, organized sports closures, online learning, staying at home, and reduced in-person contact.
COVID-19 concern

concern

\author{
Understanding \\ -transmission \\ -symptoms \\ -severity \\ Health concerns \\ -family and friends \\ -self \\ Prevention \\ -hand washing \\ -staying at home \\ -limiting contact with people
}

What children understand about COVID19, the reasons for COVID-19 restrictions, mechanisms for transmission, symptoms, and severity. How concerned they are about themselves, family, and friends getting sick and the importance of prevention.

What aspects of daily living helped mitigate the mental well-being effects of COVID-19 restrictions.

\section{Examples}

"I don't understand why we can't do these things ... I don't understand why I can't go to the playground" "He's like, 'I thought we were going to get to go back to normal at some point.' And he was really excited about starting kindergarten and he was like, 'I don't get to do that?"' "I think the impact is coming from just the extensive amount of time that we have all spent in the same house"

"She's definitely been very up and down. She really missed seeing friends, missed seeing extended family, missed going places. She really missed school, that was really hard for her ..."

"He misses his friends a lot. When we drive by the school, he gets pretty emotional ..."

"He talks about a matter-of-factly. 'Well, we can't do X, Y, and Z because of the germs. Are the germs going to be over yet so that we can do $X, Y$, and $Z$ ? or we have to wash your hands because of the germs are outside'"

"He asks lots of questions about it and on occasion he will express concern like, "Will I get sick? Are you sick? Are you going to get sick?" "Her concern would just be if her or a family member would become ill, what would become of it, that's her fear."

"She is concerned about it when we started kind of seeing like grandparents again, she was nervous to hug them or touch them or get too close to them ... So it definitely made her more cautious."

"Staying active is key during this time."

"As the weather got better and we could be outside doing more, I think some of that was alleviated just because he didn't feel so confined." "They do a lot of FaceTime and some of those apps like House Party and things like that so they can actually see each other and talk and a group of them being together." "I did notice that once the learning plan started up and they were having the Zoom calls with their teachers and she could talk to her friends... her mood greatly improved. And she hasn't been as affected since then." person school. Another prominent theme developed around child understanding and concern about COVID19. Parents' discussions about COVID-19 varied with a child's age. Most parents reported their child had some level of understanding and acknowledgement that COVID-19 causes people to be sick and can be passed through contact with other people. Children seemed to take precautions seriously. Many children, especially at 
the beginning of the outbreak expressed worry and fear around their family getting sick. A final theme emerged around ways of protecting against the MWB effects of COVID-19 restrictions. Parents felt children benefited from being outside and staying active. While some parents indicated limitations in PA due to closure of parks and organized sports such as dance and soccer, many noted playing outside in a yard, riding bikes, and taking walks improved child MWB. Additionally, many parents reported the use of technology for socializing to be helpful in minimizing some of the loneliness due to COVID19 restrictions. Many children used video calls, multiplayer games, and online chats to interact with friends remotely.

\section{Discussion}

The findings of this study suggest COVID-19 restrictions in the spring and early summer of 2020 may have impacted child MWB, PA, and SB. Through a mixedmethods approach, we were able to identify potential mechanisms through which these restrictions could impact children and potential ways of mitigating these impacts. While our results are based on parent perceptions around their child's behavior and well-being during COVID-19 restrictions, this research presents novel findings during an unprecedented time, and provides foundations for further understanding about the role of COVID-19 restrictions on child MWB, PA, and SB.

Parents perceived MWB to decrease for all MWB items in the adapted child Mood and Feelings Questionnaire and $74 \%$ of parents reported worse child MWB with COVID-19 restrictions. These findings support previous research highlighting the vulnerability of child MWB to the COVID-19 pandemic [33-35]. Qualitative analysis conducted in this study suggest in-person school closures and changes to daily life (e.g. limited contact with friends and family) due to COVID-19 restrictions, contributed to worsening child MWB. Transitions to remote learning not only posed educational challenges, but according to our findings increased feelings of loneliness and unhappiness for children who missed school activities, such as school sports and socializing with friends. Participants also reported increased worry for children, noting they felt the restrictions of not seeing grandparents, attending in-person school, or being able to use the local playground, and either drew scary conclusions about COVID-19 or were unsure what to think about the COVID-19 pandemic. These findings are particularly important given many schools are continuing to be remote throughout the fall of 2020 and spring of 2021, and daily life remains altered from life prior to the COVID-19 pandemic [8-10, 12].

Another important finding of our study was the association between COVID-19 restrictions and reduced PA.
This finding adds to previous research which has found a similar association among adults and children alike [36-40]. Reduced PA is problematic not only because of the importance of PA in preventing obesity and chronic disease later in life, but also because of the associations we found between PA with perceived changes in MWB [22]. In particular, the amount of time playing outside was perceived by parents to have the greatest impact on changes in MWB during COVID-19 restrictions. During interviews parents reported their child missed activities like playing on the local playground and spending time outside with friends. Parents in our study overwhelmingly felt their child's mood and behavior improved after spending time outside playing in the yard, riding bikes, or taking walks with family. This finding supports previous research suggesting outside play and connection with nature have benefits for mental health and concentration [41-44].

We did not find associations between time spent sitting and changes in MWB after adjusting for age. However, many parents we interviewed, noted that not having the structure of in-person school, along with the added screen time of remote learning, increased SB and in particular time spent sitting, which was often reported to be difficult for children. Parents felt their child's mood and behavior were negatively impacted, citing how their child often complained of boredom and difficulty concentrating in the remote learning environment. The differences between our quantitative and qualitative findings regarding $\mathrm{SB}$ and child $\mathrm{MWB}$, highlight the need for more research into the potential impact of age on child experiences during COVID-19.

With ongoing restrictions, efforts should be directed toward increasing socialization remotely, improving communication with children about COVID-19, and finding ways to increase $\mathrm{PA}$ and reduce $\mathrm{SB}$ during the COVID-19 pandemic. One way many parents identified as an opportunity to increase socialization was through the use of technology. Many parents felt using technology to socialize through multi-player games, video calls, and social media alleviated some of the loneliness their children were feeling due to COVID-19 restrictions. These findings align with research highlighting how technology can be used to maintain social connection during the COVID-19 pandemic [45, 46]. While technology may help improve social connection remotely, it can also lead to increased SB and adverse health outcomes such as increased risk of obesity and poor mental health [47-49]. As such, it is important to consider the balance between the need for socializing to protect against loneliness and the imperative to reduce time spent sitting in front of a screen. Some potential alternatives may be more active socializing through technology [50-53]. Examples of technology use for being active and social 
could include a dance class over video call or remote yoga with friends. As COVID-19 restrictions continue, schools may find it beneficial to use technology to create virtual physical education classes, where students can be active while interacting. School interventions and policies should focus on incorporating technology into the remote learning space that promotes PA and supports social connection amongst students.

In discussing child worry and concern about COVID19 , many parents in this sample reported children often worried less after having conversations about restrictions being in place to prevent the transmission of COVID-19 and ways family and friends were protecting themselves from becoming sick. Having these conversations in ageappropriate ways may help alleviate worry and fear some children might experience due to the COVID-19 pandemic and associated restrictions. The Centers for Disease Control and Prevention (CDC) have disseminated guidelines on the importance of communicating with children about COVID-19 and how to speak with children of different ages [54]. Other organizations have also supported age appropriate discussion with children, being open to a child's questions, and keeping lines of communication open $[55,56]$. Further, schools can act as important sources of information for parents on how to have age appropriate conversations. Collaboration between schools and parents of elementary school aged children should be ongoing to facilitate communication about COVID-19 and how to talk with children about the ongoing pandemic.

Our findings on PA and SB suggest a need for interventions and policies to promote PA and reduce SB during the COVID-19 pandemic and associated restrictions. Outside play was perceived to have the greatest impact on changes in child MWB, which may provide opportunities to promote PA in warmer months but suggests PA may decrease in winter months. While weather is conducive to outdoor activity, family walks or bike rides outside and making time each day for playing in the yard may be options. Additionally, outdoor activity can provide safer conditions for socializing aligning with recommendations for preventing the spread of COVID-19 [57]. If weather is not conducive to outdoor play, children should be encouraged to spend 10-15 minutes being active indoors through activities such as stretching, sit-ups or jumping jacks for every hour spent sitting in front of a screen [58]. Activity breaks will aid in maintaining levels of PA when being active outside due to weather is not an option. Schools should incorporate these short exercises into the remote learning setting. Class time PA breaks have been shown to be effective for increasing PA and preventing obesity in the elementary school population [59,60]. Adapting PA breaks to remote learning may help children maintain PA levels during COVID-19 restrictions and through colder weather when outside play is not as feasible.

There are a few limitations of this study. First, the convenience sample is small and homogeneous, limiting some opportunities for analysis and generalizability of findings to other populations. While the survey overall had 245 respondents, we were only able to conduct analysis on the 144 respondents who completed the adapted child Mood and Feelings questionnaire. Second, this study was cross-sectional in nature. As such, we can only assess associations between child MWB, PA, and SB during COVID-19 restrictions and cannot make causal inferences. Third, since we only collected data during the months of May through July, our study cannot assess how a longer time spent at home, or how time of year and weather might impact child MWB, PA, and SB. Finally, measures of change in MWB, PA, and SB relied on parent-report and were subject to recall bias. We also did not collect data on weekly minutes of moderate and vigorous PA, limiting our ability to use U.S. physical activity guidelines to assess perceived changes in child PA. Although limited by sample size and parent-report, this study used a mixed methods approach, which provided context and corroboration for quantitative findings from the online survey. Findings of this study also help contribute to new research in the area of COVID-19 and specifically for how COVID-19 restrictions impact children.

\section{Conclusion}

This study captured perceived changes in MWB, PA and $\mathrm{SB}$ at the start of the COVID-19 pandemic through a mixed-methods approach. Based on our findings, COVID-19 had a significant impact on child MWB, with children experiencing worse MWB due to COVID-19 restrictions. According to parents in this study, child PA behaviors decreased, SB increased with COVID-19 restrictions and maintaining or increasing child PA levels and activities acted as a protective factor for child MWB. Our results indicate monitoring child MWB, PA and SB during this ongoing pandemic is critical to identify ways to intervene and prevent potential long-term consequences of poor $\mathrm{MWB}$, decreased $\mathrm{PA}$, and increased SB. Schools and parents should look towards communicating with children about the COVID-19 pandemic to reduce fear and worry, increasing outdoor PA as weather permits, and incorporating short activities to break up SB and maintain PA levels.

As the COVID-19 pandemic and associated restrictions continue, ongoing research will be needed to determine effective interventions for child MWB and ways of keeping children active and healthy during these unprecedented times. More information is needed on how COVID-19 restrictions may differentially impact 
children by race and ethnicity, socioeconomic status, and urbanicity. Additionally, with COVID-19 restrictions ongoing, it will be critical to determine the role of seasonality and duration of COVID-19 restrictions on child MWB, PA, and SB. While this study contributes to an initial understanding of how COVID-19 restrictions may impact child MWB, PA, and SB, more research will be needed to more fully understand both immediate and long-term outcomes for children.

\author{
Abbreviations \\ COVID-19: Coronavirus disease 2019; MWB : Mental well-being; PA : Physical \\ activity; SB: Sedentary behavior
}

\section{Supplementary Information}

The online version contains supplementary material available at https://doi. org/10.1186/s12889-021-11805-6.

Additional file 1: Supplement 1. Online Questionnaire

\section{Acknowledgements}

The authors would like to thank Rebekah Jacob for assisting in data cleaning and management and the parents who participated in the interviews. This publication was made possible by Grant Number T32 HL130357 from the National Heart, Lung, and Blood Institute (NHLBI), National Institutes of Health. The content is solely the responsibility of the authors and does not necessarily represent the official views of the $\mathrm{NIH}$.

\section{Authors' contributions}

AG assisted in developing the quantitative survey and key informant interviews. Conducted key informant interviews, analyzed qualitative and quantitative data, and was a major contributor to writing the manuscript. MK assisted in developing the quantitative survey and key informant interviews. Reviewed and provided edits for manuscript. SM assisted in developing the quantitative survey and key informant interviews. Reviewed and provided edits for manuscript. LS Conducted key informant interviews, analyzed qualitative and quantitative data, and reviewed manuscript for edits. AB assisted in developing the quantitative survey and key informant interviews, conducted key informant interviews, and reviewed and provided edits for manuscript. AE assisted in developing the quantitative survey and key informant interviews. Conducted key informant interviews and analyzed qualitative data. Reviewed and provided edits for manuscript. All authors read and approved the final manuscript.

\section{Funding}

This study was funded by the Centers for Disease Control and Prevention U48DP006395. The funder had no role in data collection, data analysis, or input on the final manuscript.

\section{Availability of data and materials}

The datasets generated and/or analyzed during the current study are available from the corresponding author on reasonable request.

\section{Declarations}

\section{Ethics approval and consent to participate}

The Institutional Review Board at Washington University in St. Louis deemed this study to be of a minimal risk to participants, and the study was approved as exempt (IRB\#'s 202004224, 202004225). All participants were provided with the reason for the study. Participants taking the online survey provided consent through the online survey and participants being interviewed provided verbal consent. Both types of consent were approved by the ethics committee.

\section{Consent for publication}

Not applicable.

\section{Competing interests}

The authors declare that they have no competing interests.

Received: 4 November 2020 Accepted: 15 September 2021

Published online: 28 September 2021

\section{References}

1. The Centers for Disease Control and Prevention. CDC COVID Data Tracker. https://covid.cdc.gov/covid-data-tracker/?CDC_AA_refVal= https\%3A\%2F\%2Fwww.cdc.gov\%2Fcoronavirus\%2F2019-ncov\%2Fcasesupdates\%2Fcases-in-us.html\#cases_totalcases. Published 2020. Accessed August 15, 2021.

2. World Health Organization. WHO Coronavirus Disease (COVID-19) Dashboard. https://covid19.who.int/. Published 2020. Accessed August 15, 2021.

3. Tull MT, Edmonds KA, Scamaldo KM, Richmond JR, Rose JP, Gratz KL. Psychological outcomes associated with stay-at-home orders and the perceived impact of COVID-19 on daily life. Psychiatry Res. 2020;289(April): 113098. https://doi.org/10.1016/j.psychres.2020.113098.

4. Brooks SK, Webster RK, Smith LE, Woodland L, Wessely S, Greenberg N, et al. The psychological impact of quarantine and how to reduce it: rapid review of the evidence. Lancet. 2020;395(10227):912-20. https://doi.org/10.1016/ S0140-6736(20)30460-8.

5. Lades LK, Laffan K, Daly M, Delaney L. Daily emotional well-being during the COVID-19 pandemic. Br J Health Psychol. 2020;25(4):1-10. https://doi.org/1 0.1111/bjhp.12450.

6. Prime $H$, Wade $M$, Browne DT. Risk and resilience in family well-being during the COVID-19 pandemic. Am Psychol. 2020;75(5):631-43. https://doi. org/10.1037/amp0000660.

7. Lee J. Mental health effects of school closures during COVID-19. Lancet Child Adolesc Heal. 2020;4(6):421. https://doi.org/10.1016/S2352-4642(20)301 09-7.

8. Loades ME, Chatburn E, Higson-Sweeney N, et al. Rapid systematic review: the impact of social isolation and loneliness on the mental health of children and adolescents in the context of COVID-19. American Academy of Child \& Adolescent Psychiatry; 2020. https://doi.org/10.1016/j.jaac.2020.05. 009.

9. Saurabh K, Ranjan S. Compliance and psychological impact of quarantine in children and adolescents due to Covid-19 pandemic. Indian J Pediatr. 2020; 87(7):532-6. https://doi.org/10.1007/s12098-020-03347-3.

10. Gupta S, Jawanda MK. The impacts of COVID-19 on children. Acta Paediatr Int J Paediatr. 2020;109(11):2181-3. https://doi.org/10.1111/apa.15484.

11. Commisioner C's. Childhood in the time of Covid. London; 2020.

12. Golberstein E, Wen H, Miller B. Coronavirus disease 2019 (COVID-19) and mental health for children and adolescents. JAMA Pediatr. 2020;28(8):95570. https://doi.org/10.1002/hec.3885.

13. Golberstein E, Gonzales G, Meara E. How do economic downturns affect the mental health of children? Evidence from the National Health Interview Survey. Heal Econ (United Kingdom). 2019;28(8):955-70. https://doi.org/10.1 002/hec.3885

14. Qin F, Song Y, Nassis GP, Zhao L, Dong Y, Zhao C, et al. Physical activity, screen time, and emotional well-being during the 2019 novel coronavirus outbreak in China. Int J Environ Res Public Health. 2020;17(14):1-16. https:// doi.org/10.3390/ijerph17145170.

15. Tison G, Avram R, Kuhar P, et al. Worldwide Effect of COVID-19 on Physical Activity: A Descriptive Study. Ann Intern Med. 2020;(March):1-3. https://doi. org/10.7326/M20-2665.

16. Dwyer MJ, Pasini M, De Dominicis S, Righi E. Physical activity: benefits and challenges during the COVID-19 pandemic. Scand J Med Sci Sports. 2020; 30(7):1291-4. https://doi.org/10.1111/sms.13710.

17. Ahn S, Fedewa AL. A meta-analysis of the relationship between children's physical activity and mental health. J Pediatr Psychol. 2011;36(4):385-97. https://doi.org/10.1093/jpepsy/jsq107.

18. Biddle SJH, Ciaccioni S, Thomas G, Vergeer I. Physical activity and mental health in children and adolescents: an updated review of reviews and an analysis of causality. Psychol Sport Exerc. 2019;42(August 2018):146-55. https://doi.org/10.1016/j.psychsport.2018.08.011.

19. Suchert $V$, Hanewinkel $R$, Isensee $B$. Sedentary behavior and indicators of mental health in school-aged children and adolescents: A systematic review. Prev Med (Baltim). 2015;76:48-57. https://doi.org/10.1016/j.ypmed.2 015.03.026. 
20. Rodriguez-Ayllon M, Cadenas-Sánchez C, Estévez-López F, Muñoz NE, MoraGonzalez J, Migueles JH, et al. Role of physical activity and sedentary behavior in the mental health of preschoolers, children and adolescents: a systematic review and Meta-analysis. Sports Med. 2019;49(9):1383-410. https://doi.org/10.1007/s40279-019-01099-5.

21. Wade M, Prime $H$, Browne DT. Why we need longitudinal mental health research with children and youth during (and after) the COVID-19 pandemic. Psychiatry Res. 2020;290(May):113143. https://doi.org/10.1016/j. psychres.2020.113143.

22. Physical Activity Guidelines Advisory Committee. 2018 Physical Activity Guidelines Advisory Committee. Vol 2018. Washington, DC; 2018. doi:https:// doi.org/10.1111/j.1753-4887.2008.00136.x, 2, 114, 120.

23. Howie EK, McVeigh JA, Smith AJ, et al. Physical activity trajectories from childhood to late adolescence and their implications for health in young adulthood. Prev Med (Baltim). 2020;139(April). https://doi.org/10.1016/j. ypmed.2020.106224.

24. Wu XY, Bastian K, Ohinmaa A, Veugelers P. Influence of physical activity, sedentary behavior, and diet quality in childhood on the incidence of internalizing and externalizing disorders during adolescence: a populationbased cohort study. Ann Epidemiol. 2018;28(2):86-94. https://doi.org/10.101 6/j.annepidem.2017.12.002.

25. Jacka FN, Pasco JA, Williams LJ, Leslie ER, Dodd S, Nicholson GC, et al. Lower levels of physical activity in childhood associated with adult depression. J Sci Med Sport. 2011;14(3):222-6. https://doi.org/10.1016/j.jsa ms.2010.10.458.

26. Van Ekris E, Altenburg TM, Vos EE, Chinapaw MJM. An evidence-update on the prospective relationship between childhood sedentary behaviour and biomedical health indicators: a systematic review and meta-analysis. Obes Rev. 2016;17(9):833-49. https://doi.org/10.1111/obr.12426.

27. Ekelund U, Luan J, Sherar LB, Esliger DW, Griew P, Cooper A. Moderate to vigorous physical activity and sedentary time and cardiometabolic risk factors in children and adolescents. JAMA. 2012;307(7):704-12. https://doi. org/10.1001/jama.2012.156.

28. Wu XY, Han LH, Zhang JH, Luo S, Hu JW, Sun K. The influence of physical activity, sedentary behavior on health-related quality of life among the general population of children and adolescents: a systematic review. PLoS One. 2017;12(11):1-15. https://doi.org/10.1371/journal.pone.0187668.

29. Syväoja HJ, Tammelin TH, Ahonen T. Kankaanpaä a, Kantomaa MT. the associations of objectively measured physical activity and sedentary time with cognitive functions in school-aged children. PLoS One. 2014;9(7):1-10. https://doi.org/10.1371/journal.pone.0103559.

30. Schoonenboom J, Johnson RB. How to construct a mixed methods research design. Kolner Z Soz Sozpsychol. 2017;69(S2):107-31. https://doi.org/10.1 007/s11577-017-0454-1.

31. Angold A, Costello EJ, Messer SC, Pickles A, Winder F, Silver D. The development of a short questionnaire for use in epidemiological studies of depression in children and adolescents. Int J Methods Psychiatr Res. 1995;5: 237-49.

32. Vaughn A, Hales D, Neshteruk C, Ward D. HomeSTEAD's physical activity and screen media practices and beliefs survey: Instrument development and integrated conceptual model. PLoS One. 2019;14(12). https://doi.org/1 0.1371/journal.pone.0226984.

33. Green P. Risks to children and young people during covid-19 pandemic. BMJ. 2020;369(April):1-2. https://doi.org/10.1136/bmj.m1669.

34. Thakur K, Kumar N, Sharma NR. Effect of the pandemic and lockdown on mental health of children. Indian J Pediatr. 2020;87(7):552. https://doi.org/1 0.1007/s12098-020-03308-w.

35. Fore HH. A wake-up call: COVID-19 and its impact on children's health and wellbeing. Lancet Glob Health. 2020;8(7):e861-2. https://doi.org/10.1016/ S2214-109X(20)30238-2.

36. Hall G, Laddu D, Phillips S. A tale of two pandemics : How will COVID-19 and global trends in physical inactivity and sedentary behavior affect one another? Prog Cardiovasc Dis. 2020;2021(January). https://doi.org/10.1016/j. pcad.2020.04.005.

37. Rundle AG, Park Y, Herbstman JB, Kinsey EW, Wang YC. COVID-19-related school closings and risk of weight gain among children. Obesity. 2020;28(6): 1008-9. https://doi.org/10.1002/oby.22813.

38. Jurak G, Morrison SA, Leskošek B, Kovač M, Hadžić V, Vodičar J, et al. Physical activity recommendations during the coronavirus disease-2019 virus outbreak. J Sport Health Sci. 2020;9(4):325-7. https://doi.org/10.1016/j.jshs.2 020.05.003.
39. Lesser IA, Nienhuis CP. The impact of COVID-19 on physical activity behavior and well-being of canadians. Int J Environ Res Public Health. 2020; 17(11). https://doi.org/10.3390/ijerph17113899.

40. Dunton GF, Do B, Wang SD. Early effects of the COVID-19 pandemic on physical activity and sedentary behavior in children living in the U.S. BMC Public Health. 2020;20(1):1351. https://doi.org/10.1186/s12889-02009429-3.

41. Chawla L, Keena K, Pevec I, Stanley E. Green schoolyards as havens from stress and resources for resilience in childhood and adolescence. Health Place. 2014;28:1-13. https://doi.org/10.1016/j.healthplace.2014.03.001.

42. Piccininni C, Michaelson V, Janssen I, Pickett W. Outdoor play and nature connectedness as potential correlates of internalized mental health symptoms among Canadian adolescents. Prev Med (Baltim). 2018;112(April): 168-75. https://doi.org/10.1016/j.ypmed.2018.04.020.

43. Huynh Q, Craig W, Janssen I, Pickett W. Exposure to public natural space as a protective factor for emotional well-being among young people in Canada. BMC Public Health. 2013;13(1). https://doi.org/10.1186/1471-24 58-13-407.

44. McCurdy LE, Winterbottom KE, Mehta SS, Roberts JR. Using nature and outdoor activity to improve children's health. Curr Probl Pediatr Adolesc Health Care. 2010;40(5):102-17. https://doi.org/10.1016/j. cppeds.2010.02.003

45. Goldschmidt K. The COVID-19 pandemic: technology use to support the wellbeing of children. J Pediatr Nurs. 2020;53:88-90. https://doi.org/10.1016/ j.pedn.2020.04.013.

46. Saltzman LY, Hansel TC, Bordnick PS. Loneliness, isolation, and social support factors in post-COVID-19 mental health. Psychol Trauma Theory Res Pract Policy. 2020;12(S1):55-7. https://doi.org/10.1037/tra0000703.

47. Leblanc AG, Katzmarzyk PT, Barreira TV, et al. Correlates of Total Sedentary Time and Screen Time in 9-11 Year-Old Children around the World : The International Study of Childhood Obesity, Lifestyle and the Environment. PLoS One. 2015;6(10):1-10. https://doi.org/10.1371/journal.pone.0129622.

48. Poitras VJ, Gray CE, Janssen X, et al. Systematic review of the relationships between sedentary behaviour and health indicators in the early years (0-4 years). BMC Public Health. 2017;17(Suppl 5). https://doi.org/10.1186/s12889017-4849-8.

49. Babic MJ, Smith JJ, Morgan PJ, Eather N, Plotnikoff RC, Lubans DR. Longitudinal associations between changes in screen-time and mental health outcomes in adolescents. Ment Health Phys Act. 2017;12:124-31. https://doi.org/10.1016/j.mhpa.2017.04.001.

50. Biddiss E, Irwin J. Active video games to promote physical activity in children and youth: a systematic review. Arch Pediatr Adolesc Med. 2010; 164(7):664-72. https://doi.org/10.1001/archpediatrics.2010.104.

51. Witherspoon L, Manning J. Active gaming: the future of play? Am J Play. 2012;4(4):464-87 http://eric.ed.gov/?id=EJ985601.

52. Nagata JM, Abdel Magid HS, Pettee GK. Screen time for children and adolescents during the coronavirus disease 2019 pandemic. Obesity. 2020; 28(9):1582-3. https://doi.org/10.1002/oby.22917.

53. Tate DF, Lyons EJ, Valle CG. High-tech tools for exercise motivation: use and role of technologies such as the internet, mobile applications, social media, and video games. Diabetes Spectr. 2015;28(1):45-54. https://doi.org/10.2337/ diaspect.28.1.45

54. Centers for Disease Control and Prevention. Talking with children about Coronavirus Disease 2019. https://www.cdc.gov/coronavirus/2019-ncov/da ily-life-coping/talking-with-children.html. Published 2020. Accessed October 2, 2020.

55. Ehmke R. Talking to Kids About the Coronavirus Crisis. Child Mind Institute. https://childmind.org/article/talking-to-kids-about-the-coronavirus/. Published 2020. Accessed October 22, 2020.

56. National Association of School Psychologists and National Association of School Nurses. Talking to Children About COVID-19 (Coronavirus): A Parent Resource. Vol 19. Bethesda; 2020. https://www.nasponline.org/resources-a nd-publications/resources-and-podcasts/school-climate-safety-and-crisis/hea Ith-crisis-resources/helping-children-cope-with-changes-resulting-fromcovid-19.

57. World Health Organization. Transmission of SARS-CoV-2 : implications for infection prevention precautions. 2020;(July):1-10.

58. Chen P, Mao L, Nassis GP, Harmer P, Ainsworth BE, Li F. Coronavirus disease (COVID-19): the need to maintain regular physical activity while taking precautions. J Sport Health Sci. 2020;9(2):103-4. https://doi.org/10.1016/j. jshs.2020.02.001. 
59. Carlson JA, Engelberg JK, Cain KL, Conway TL, Mignano AM, Bonilla EA, et al. Implementing classroom physical activity breaks: associations with student physical activity and classroom behavior. Prev Med (Baltim). 2015;81:67-72. https://doi.org/10.1016/j.ypmed.2015.08.006.

60. Kibbe DL, Hackett J, Hurley M, et al. Ten Years of TAKE 10!: Integrating physical activity with academic concepts in elementary school classrooms. Prev Med (Baltim). 2011;52(SUPPL):S43-50. https://doi.org/10.1016/j.ypmed.2 011.01.025.

\section{Publisher's Note}

Springer Nature remains neutral with regard to jurisdictional claims in published maps and institutional affiliations.

- fast, convenient online submission

- thorough peer review by experienced researchers in your field

- rapid publication on acceptance

- support for research data, including large and complex data types

- gold Open Access which fosters wider collaboration and increased citations

- maximum visibility for your research: over $100 \mathrm{M}$ website views per year

At $\mathrm{BMC}$, research is always in progress. 